Materiales de Construcción

Vol. 68, Issue 330, April-June 2018, e154

ISSN-L: 0465-2746

https://doi.org/10.3989/mc.2018.11316

\title{
A composite cement of high magnesium sulphate resistance
}

\author{
A. Allahverdi ${ }^{\mathrm{a}}$,, M. Akhondi ${ }^{\mathrm{a}}$, M. Mahinroosta ${ }^{\mathrm{a}} \bowtie$ \\ a. Research laboratory of Inorganic Chemical Process Technologies, School of Chemical Engineering, Iran University of Science and \\ Technology, (Tehran, Iran) \\ b. Cement Research Center, Iran University of Science and Technology, (Tehran, Iran) \\ $\triangle$ mahinroosta2010@gmail.com
}

\begin{abstract}
This study investigates the magnesium sulphate resistance of chemically activated phosphorus slag-based composite cement (CAPSCC). Enough mortar specimens were prepared from phosphorus slag ( 80 wt. \%), type II Portland cement (14 wt.\%), and compound chemical activator (6 wt.\%) and were exposed to 5\% magnesium sulphate solution after being cured. Mortar specimens of both type II and V Portland cements (PC2 and PC5) were also prepared and used for comparison purpose. According to the test results, after 12 months of exposure, PC2, PC5 and CAPSCC exhibited 43.5, 35.2 and 25.2\% reduction in compressive strength, 0.136 , 0.110 , and $0.026 \%$ expansion in length, and $0.91,2.2$, and $1.78 \%$ change in weight, respectively. Complementary studies by X-ray diffractometry and scanning electron microscopy revealed that CAPSCC has a very low potential for the formation of sulphate attack products, especially ettringite. The results confirm a high magnesium sulphate resistance for CAPSCC compared to PC2 and PC5.
\end{abstract}

KEYWORDS: Composite; Blended cement; Sulphate-resistant cement; Sulphate attack; Compressive strength

Citation/Citar como: Allahverdi, A.; Akhondi, M.; Mahinroosta, M. (2018) A composite cement of high magnesium sulphate resistance. Mater. Construcc. 68 [330], e154 https://doi.org/10.3989/mc.2018.11316

RESUMEN: Cemento compuesto de alta resistencia al sulfato de magnesio. Este trabajo aborda el estudio de la resistencia al sulfato de magnesio de un cemento compuesto con base de escoria de fósforo activada químicamente (CAPSCC). Se prepararon muestras de mortero a partir de escoria de fósforo ( $80 \%$ en peso), cemento Portland tipo II ( $14 \%$ en peso) y activador químico ( $6 \%$ en peso) y tras el curado, se expusieron a una solución de sulfato de magnesio al 5\%. También se prepararon morteros de cementos Portland de tipo II y V (PC2 y PC5) que se usaron con fines comparativos. De acuerdo a los resultados obtenidos, después de 12 meses de exposición, PC2, PC5 y CAPSCC mostraron un 43.5, 35.2 y 25.2\% de reducción en la resistencia a la compresión, $0.136,0.110$, y $0.026 \%$ de expansión en longitud, y $0.91,2.2$ y $1.78 \%$ de cambio en peso, respectivamente. Estudios complementarios por difracción de rayos X y microscopía electrónica de barrido revelaron que los cementos CAPSCC tienen un potencial muy bajo para la formación de productos de ataque de sulfato, especialmente etringita. Los resultados confirman una alta resistencia al sulfato de magnesio para CAPSCC en comparación con PC2 y PC5

PAlabRaS ClaVE: Composite; Cemento con adiciones; Cementos resistentes a los sulfatos; Ataque por sulfatos; Resistencia a la compresión

ORCID ID: A. Allahverdi (http://orcid.org/0000-0002-8988-9226); M. Akhondi (http://orcid.org/0000-0001-67236024); M. Mahinroosta (http://orcid.org/0000-0001-9709-2949)

Copyright: (C) 2018 CSIC. This is an open-access article distributed under the terms of the Creative Commons Attribution 4.0 International (CC BY 4.0) License. 


\section{INTRODUCTION}

The world is now looking forward to the emergence of new construction and building binders that can replace the Portland cement and not only increase environmental sustainability but also improve the durability and performance of concrete structures (1). Structural durability and performance over the long-term exploitation have vital importance for the safe and efficient concrete construction (2). Degradation of concrete exposed to aggressive environments such as seawater, wastewater, and atmospheric pollution leading to acid rain is a key issue, which causes problems affecting life cycle, performance, and costs of maintenance of civil infrastructures (3-6). Despite numerous studies, this field, especially enhancing the performance and durability of concrete and mortar in aggressive environments requires further study $(3,5)$. Durability and performance of concrete are determined through its ability to resist against abrasion, chemical attack or any other destructive process. In the case of chemical attack, sulphate attack is one of the fundamental causes of the degradation of concrete and consequently destruction of concrete structures followed by costly detriments. The effect of sulphate attack depends on the composition and type of cement used, the nature and concentration of sulphate solution, the presence of various cations in sulphate environment, and the concrete and mortar quality $(2,3,7)$. Therefore, studying the performance of concrete and mortar in contact with sulphate environments requires further attention and investigation (7).

\subsection{Sulphate attack overview}

Chemical reactions between sulphates and cement paste constituents are one of the most important reasons for concrete degradation (8-10). Sulphates attack cement hydration products, especially calcium hydroxide $(\mathrm{CH})$, calcium silicate hydrate $(\mathrm{CSH})$, and calcium aluminate hydrate $(8,10-12)$. The mechanism of the attack depends on the type of sulphate environment and hydration reaction products (8). The sulphate attack rate is dependent upon availability to $\mathrm{CH}$ and tricalcium aluminate $\left(\mathrm{C}_{3} \mathrm{~A}\right)$ in hydrated concrete $(10,13)$. The higher the amount of $\mathrm{CH}$ and $\mathrm{C}_{3} \mathrm{~A}$ in hardened paste, the more vulnerability against sulphate attack. Low- $\mathrm{C}_{3} \mathrm{~A}$ cements exhibit good sulphate resistance, however, the use of these types of cements in exposure to magnesium sulphate or sulfuric acid can be harmful (14). The amount of tricalcium silicate $\left(\mathrm{C}_{3} \mathrm{~S}\right)$ or ratio of $\mathrm{C}_{3} \mathrm{~S} /$ dicalcium silicate $\left(\mathrm{C}_{2} \mathrm{~S}\right)$ also can be effective on the sulphate resistance of cement. Increase of $\mathrm{C}_{3} \mathrm{~S}$ in cement causes enhancement of $\mathrm{CH}$ formation in hardened cement paste, which in turn reduces the sulphate resistance of cement (13). In the case of magnesium sulphate attack, the first stage is the reaction between sulphate ions and $\mathrm{CH}$ followed by the production of brucite (magnesium hydroxide) and gypsum $(8,15)$. Brucite deposits on the exposed surface and creates a temporary protective layer against the diffusion of sulphate ions. With degradation of this layer due to the continuation of sulphate attack and decrease in concentration of $\mathrm{CH}$ because of its reaction with sulphate ions, deterioration of $\mathrm{CSH}$ begins resulting in the formation of gypsum, brucite, and silica gel. With more protraction of sulphate ion attack, magnesium silicate hydrate is formed $(11,12,15,16)$.

Due to pozzolanic property, the use of mineral admixtures that decreases the $\mathrm{CH}$ content of the cement paste and results in dilution of calcium aluminate hydrate can improve sulphate resistance $(11,14,17,18)$. Composite cements containing pozzolanic materials also create a more compact structure with lower permeability compared to ordinary Portland cement that causes the diffusion of invasive ions into hydration products to be more difficult $(1,19)$. Pozzolan-containing cements do not have a desirable performance in magnesium sulphate solutions, because two temporary surface layers of brucite and gypsum are formed, which finally result in easier diffusion of aggressive ions inwards after they are cracked and broken down. Moreover, the consumption of $\mathrm{CH}$ decreases the $\mathrm{pH}$ of the pore solution of the cement paste resulting in the degradation of CSH (14). In concrete and mortars exposed to magnesium sulphate, the degradation is observed in the forms of compressive strength reduction, weight and length changes, and decreased adhesion caused by the decomposition of $\mathrm{CSH}$ and also formation of gypsum (20).

One of the important factors affecting the degradation of concrete exposed to sulphate environment is the concentration of sulphate. Relatively higher concentrations of sulphate lead to faster concrete degradation (13). Increased concentrations of sulphate ions in magnesium sulphate solution result in the enhancement of expansion. It is noteworthy to say that long-term exposure to sulphate solutions of relatively low concentrations is more effective on concrete degradation than short-term exposure to sulphate solutions of relatively high concentrations (21). Physical conditions of exposure to sulphate solutions such as temperature, wet/dry cycles, and partial or full immersion are also effective on the rate of concrete degradation. Increase in temperature of sulphate solution leads to the increase of the degradation rate $(13,22)$. Decrease in temperature of sulphate solution to about 0 to $5{ }^{\circ} \mathrm{C}$, however, results in the decomposition of $\mathrm{CSH}$ and formation of thaumasite (23). The effect of wetting/ drying cycles, especially in conditions that the 
transformation of crystalline sulphate salts occurs, results in the enhancement of concrete degradation (24).

\subsection{Research background}

In various studies, magnesium sulphate resistance of blended cements prepared by different supplementary cementing materials such as granulated blast furnace slag (GBFS), silica fume, and fly ash has been investigated (25-36). Through doing a literature survey, it can be found out that very limited studies have been conducted on the resistance of phosphorus slag (PHS) content cements against sulphate attack so that the resistance of these types of blended cements is not well known. Most of studies have evaluated the sulphate resistance of cements containing GBFS, silica fume, and fly ash for relatively short exposure times. For example, Samanta and Chatterjee (25) conducted a study in this area and concluded that initial increase of compressive strength up to a maximum value followed by the occurrence of a declining trend can be dependent on the mode of formation of ettringite in the set cement. Duda (26) showed that BFS-PC cement is magnesium sulphate-resistant correlated well with its decreased capillary pore volume and low Portlandite contents. Torii and Kawamura (27) stated that the replacement of Portland cement by fly ash and silica fume effectively tailored the resistance of the mortar specimens in the long-term exposure to magnesium sulfate solution attack. Gollop and Taylor (28) generally mentioned that the resistance to attack by suhphate ions, is favored by the use of high proportions of slag. Similar conclusion has been drawn by Al-Amoudi (29). Zelić et al. (30) investigated the effect of silica fume on corrosion resistance to sulphate attack and observed better durability performance of cement containing silica fume due to the less $\mathrm{CH}$ formation by the hydration reactions and consequently less gypsum and ettringite during the sulphate immersion of mortars. Aköz et al. (31) showed that silica fume replacement causes significant increase in sulfate resistance of mortar even at highest sulfate concentration. Lee et al. (32), Diab et al. (33), and İnan Sezer (34), however, reported a different behavior in which mortars with silica fume were severely damaged in the magnesium sulfate environment. Biricik and his colleagues (35) and also Chatveera and Lertwattanaruk (36) studied magnesium and sodium sulfate resistance of mortars containing wheat straw ash and observed a proper sulphateresistance. Chindaprasirt et al. (37) proved that silica fume improved the strength and resistance to sulfate of fly ash-based geopolymer. Nehdi et al. (38) proposed that partial replacement of cement with pozzolanic complementary materials can improve strength behavior of cement. Saca and Georgescu (39) in their study showed that the presence of both limestone and fly ash in cement does not seem to decrease the vulnerability of cements to magnesium sulfate attack at low temperature. Yusuf (40) in a new study on mortar prepared from combination of palm oil fuel ash and slag reported that this type of cement provides good resistance to sulfate attack.

As can be deduced from the above-mentioned reports, there are inconsistent results about the role of supplementary cementing materials on the sulphate resistance of blended or composite cements. Taken together, these have been our initial motivation to investigate the magnesium sulphate resistance of a kind of PHS-based composite cement with a very high replacement level.

PHS is a by-product of yellow phosphor production via electric furnace method, mainly consisting of calcium oxide $(\mathrm{CaO})$ and silicon dioxide $\left(\mathrm{SiO}_{2}\right)(41,42)$. From chemical composition, it can be understood that PHS exhibits latent cementing properties with some pozzolanic character (reaction with lime), but it is less reactive than BFS. The reason is that it is relatively poor in alumina content, in addition to its phosphorus oxide content that has deep influence on setting time of cement $(41,42)$. Various properties of PHSblended cements have been investigated, and it has been determined that PHS content cements exhibit appropriate physical and mechanical properties under the effect of thermal, hydrothermal, and mechanical treatments. This type of composite cement presents 28-day compressive strength of almost $93 \mathrm{MPa}$ at relatively high Blaine fineness of $450 \mathrm{~m}^{2} / \mathrm{kg}$ and a significantly better resistance against frost-salt attack (41-45).

The cement under investigation in the present work is prepared from high amount of PHS and is chemically activated by adding a Portland cementbased compound chemical activator formed from sodium sulphate and anhydrite $(44,46)$. This new environmentally-friendly cement is named chemically-activated phosphorus slag-based composite cement (CAPSCC). The CAPSCC in the present work is prepared by proportioned mixing of PHS (80 wt.\%), PC (14 wt.\%) and compound chemical activator (6 wt.\%) (Sodium sulfate (2 wt.\%)+anhydrite (4 wt.\%)) followed by intergrinding of them using a laboratory ball mill with the length and diameter of 0.30 and $0.26 \mathrm{~m}$, respectively for a period of $7 \mathrm{~h}$ until the targeted Blaine fineness of $303 \mathrm{~m}^{2} / \mathrm{kg}$. As a new aspect, this work is devoted to investigate the resistance of CAPSCC against magnesium sulphate attack at various exposure times up to one year. Also, the magnesium sulphate resistance of CAPSCC is compared with that of type II and V Portland cements within the scope of this study. 


\section{MATERIALS AND METHODS}

\subsection{Materials}

\subsubsection{Phosphorus slag and Portland cements}

The PHS used in this study was provided from a phosphoric acid plant located in Tehran province, Iran. Type II Portland cement (PC2) and Type V Portland cement (PC5) were used in accordance with ASTM standard. The chemical and physical properties of PHS, PC2, and PC5 as well as Bogue's potential phase compositions of PCs are presented in Table 1. The chemical composition of PHS mentioned in Table 1 has been determined according to ASTM standards C311 and C114.

Figure 1 depicts the X-ray diffractogram of PHS powder indicating the presence of periclase $(\mathrm{MgO})$ as the only crystalline phase.

\subsubsection{Compound chemical activator}

A mixture of sodium sulphate $(2 \mathrm{wt} . \%)$ and anhydrite (4 wt.\%) was used as compound chemical activator in this study based on some recent studies $(47,48)$. Sodium sulphate was purchased from Merck (Darmstadt, Germany). The chemical composition of anhydrite (in wt.\%) was as follows: CaO36.00, $\mathrm{SO}_{3}-54.38$, and $\mathrm{SiO}_{2}-5.88$.

TABle 1. Properties of phosphorus slag and Portland cements

\begin{tabular}{lccc}
\hline Physical properties & PC2 & PC5 & PHS \\
\hline Blaine fineness $\left(\mathrm{m}^{2} / \mathrm{kg}\right)$ & 320 & 295 & 303 \\
Density $\left(\mathrm{kg} / \mathrm{m}^{3}\right)$ & 3120 & 3145 & $2940^{*}$ \\
Chemical composition $($ wt. $\%)$ & & \\
$\mathrm{CaO}$ & 63.26 & 64.90 & 45.14 \\
$\mathrm{SiO}_{2}$ & 22.50 & 22.42 & 38.42 \\
$\mathrm{Al}_{2} \mathrm{O}_{3}$ & 4.15 & 3.81 & 7.65 \\
$\mathrm{Fe}_{2} \mathrm{O}_{3}$ & 3.44 & 4.20 & 0.90 \\
$\mathrm{MgO}$ & 3.25 & 0.08 & 2.60 \\
$\mathrm{SO}_{3}$ & 1.80 & 1.64 & - \\
$\mathrm{K}_{2} \mathrm{O}$ & 0.65 & 0.42 & 0.56 \\
$\mathrm{Na}_{2} \mathrm{O}$ & 0.20 & 0.22 & 0.43 \\
$\mathrm{P}_{2} \mathrm{O}_{5}$ & - & - & 1.50 \\
$\mathrm{LOI}_{\text {Free lime }}$ & 0.61 & 1.61 & 1.87 \\
$\mathrm{Bogue}_{3}$ potential phase composition $($ wt. $\%)$ & - \\
$\mathrm{C}_{3} \mathrm{~S}$ & 45.62 & 53.65 & - \\
$\mathrm{C}_{2} \mathrm{~S}$ & 30.16 & 23.88 & - \\
$\mathrm{C}_{3} \mathrm{~A}$ & 5.18 & 2.99 & - \\
$\mathrm{C}_{4} \mathrm{AF}$ & 10.47 & 12.78 & - \\
\hline & 0.48 & 1.07 & \\
\hline
\end{tabular}

* In accordance with ASTM standard C188

\subsubsection{Sand}

The siliceous sand used to prepare the mortar specimens was in accordance with standard DIN-EN 196-1.

\subsubsection{Water}

The pipeline potable water was used to prepare mortar specimens. The specific gravity of the used water was supposed about $1000 \mathrm{~kg} / \mathrm{m}^{3}$.

\subsection{Methods}

\subsubsection{Preparation of specimens and solution}

Enough paste and mortar specimens of different sizes were prepared from CAPSCC and control cements (PC2, PC5) in accordance with ASTM standard C109. The water-to-cement ratios for CAPSCC paste and mortar were obtained 0.22 and 0.37 , respectively in accordance with ASTM standards C187 and C230, respectively. For CAPSCC mortar, the water-to-cement ratio was adjusted at a value giving an almost the same spread diameter as obtained for PC2 and PC5 control mortars in flow-table test. Mortar specimens of the size $5 \times 5 \times 5 \mathrm{~cm}^{3}$ were used for monitoring the changes happening in the compressive strength and weight and mortar specimens of the size $2.5 \times 2.5 \times 28.5 \mathrm{~cm}^{3}$ were employed for the purpose of length change test. Simultaneously, paste specimens of the size $2 \times 2 \times 2 \mathrm{~cm}^{3}$ were also prepared for complementary studies (XRD and SEM).

To prepare mortar specimens, a planetary mixer was used according to ASTM standard C305. After casting, the molds were stored at an atmosphere of more than $95 \%$ relative humidity at $23 \pm 2{ }^{\circ} \mathrm{C}$ for 24 hours and then after demolding, the specimens were cured in lime-saturated water at $23 \pm 2{ }^{\circ} \mathrm{C}$ until the time of testing.

The curing time in lime-saturated water for control specimens was 27 days. For CAPSCC specimens, however, based on ASTM standard C1012,

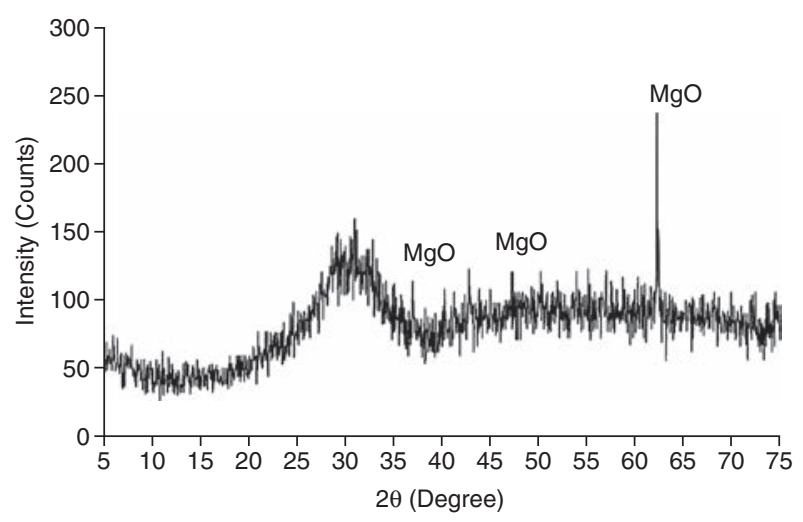

FIGURE 1. X-ray diffractogram of phosphorus slag powder. 
a curing time of 49 days in lime-saturated water was applied for attaining a compressive strength of at least $20 \mathrm{MPa}$. The magnesium sulphate solution was also prepared in accordance with ASTM standard C1012. All the cured paste and mortar specimens were then fully immersed in 5\% magnesium sulphate solution. To control the $\mathrm{pH}$ of the solution between 6 and 8, the solution was refreshed every week for the first month, and then this trend was continued every month to the end of twelfth month.

\subsubsection{Measurement techniques}

The compressive strength of the specimens was measured by means of a uniaxial digital hydraulic press (SCL STD 30) with $\pm 1 \%$ accuracy. A total of three cubic specimens were monthly used for each measurement of compressive strength and the average of them was reported as the result. The compressive strength reduction was calculated by the following equation [1]:

Compressive strength reduction $(\%)=[(B-A) / A] \times 100$

where $A$ (in $\mathrm{MPa}$ ) is the average compressive strength of three specimens after 28 days of curing and $B$ (in $\mathrm{MPa})$ is the average compressive strength of three specimens exposed to 5\% magnesium sulphate solution. The standard deviation of the compressive strength varied from $0.2 \%$ to $3 \%$.

Length change test was done in accordance with ASTM standard C1012 using comparator device with a precision of $0.01 \mathrm{~mm}$. According to this standard, length changes were calculated by the following equation [2]:

$\Delta L=\left[\left(L_{x}-L_{i}\right) / L_{g}\right] \times 100$

where $\Delta L(\%)$ is the change in length at the age of $x$; $L_{x}$ is the average comparator reading of three bars at the age of $x ; L_{i}$ is the average initial comparator reading of the same three bars; and $L_{g}$ is nominal gage length. Measurements of length change were performed after $1,2,3,4,8,13$, and 15 weeks and 4 , $5,6,7,8,10$, and 12 months of exposure to magnesium sulphate solution.

For weight change test purpose, the solution on the surfaces of the specimens was firstly removed with a towel and immediately after that the weights of the specimens were measured and recorded. Three cubic specimens were monthly used for each measurement of weight change and the average of them was reported as the result. The weight change due to exposure to magnesium sulphate solution was calculated by the following equation [3]:

$\Delta W_{x}=\left[\left(W_{x}-W_{i}\right) / W_{i}\right] \times 100$ in which, $\Delta W_{x}(\%)$ is weight change; $W_{i}$ (in g) is the average weight change of three specimens after 28 days of curing; and $W_{x}$ (in $\mathrm{g}$ ) is the average weight change of the same three specimens exposed to $5 \%$ magnesium sulphate solution.

\subsubsection{Complementary studies}

For complementary studies, the paste and mortar specimens which have been exposed to 5\% magnesium sulphate solution for 10 months were used. The mineralogical characterization was performed with a Philips PW 1800 powder X-ray diffractometer using CuK $\alpha$ radiation at $40 \mathrm{kV}$ and $30 \mathrm{~mA}$. The $\mathrm{X}$-ray diffraction (XRD) patterns were obtained by a scanning rate of $1^{\circ}$ per minute from $2 \theta=4^{\circ}$ to $60^{\circ}$. From each of the paste specimens of three cements, a complete paste specimen including surface brucite layer was crushed, dried at room temperature for 2 days and ground to a fine powder. The produced powders were then split into small samples for X-ray diffractometry test.

For the purpose of microstructural studies, SEM images were prepared from regions close to exposed surfaces of CAPSCC, PC2, and PC5 pastes and mortars using a TESCAN VEGA II Scanning Electron Microscope device (Czech Republic) at an accelerating voltage of $30 \mathrm{kV}$. For this purpose, relatively thin sections were cut from the paste and mortar specimens. These sections were then dried in an oven at a temperature of $95^{\circ} \mathrm{C}$ for 3 days. The SEM images have been prepared in the secondary electron mode of the device. To make the samples conductive, they were coated with a very thin gold layer.

\section{RESULTS AND DISCUSSION}

\subsection{Visual observation}

The deteriorating effects of sulphate attack on cement-based materials usually result in visually distinguishable signs. During the course of deterioration, the changes in the appearance of the specimens were monitored visually and photographed. Figure 2 shows PC2, PC5, and CAPSCC mortar specimens exposed to $5 \%$ magnesium solution for 12 months. As seen in this figure, after 12 months of exposure, specimens of PC5 and especially PC2 showed observable signs of deterioration at the corners and regions close to the edges. As it is clear, the greatest apparent deterioration is related to PC2 mortar specimen. In the case of PC5 mortar specimen, deterioration is fairly large, while lower signs of destruction are observable in CAPSCC mortar specimen.

\subsection{Compressive strength change}

Compressive strength reductions (\%) of $\mathrm{PC} 2$, PC5, and CAPSCC mortar specimens immersed in magnesium sulphate solution for 12 months are 


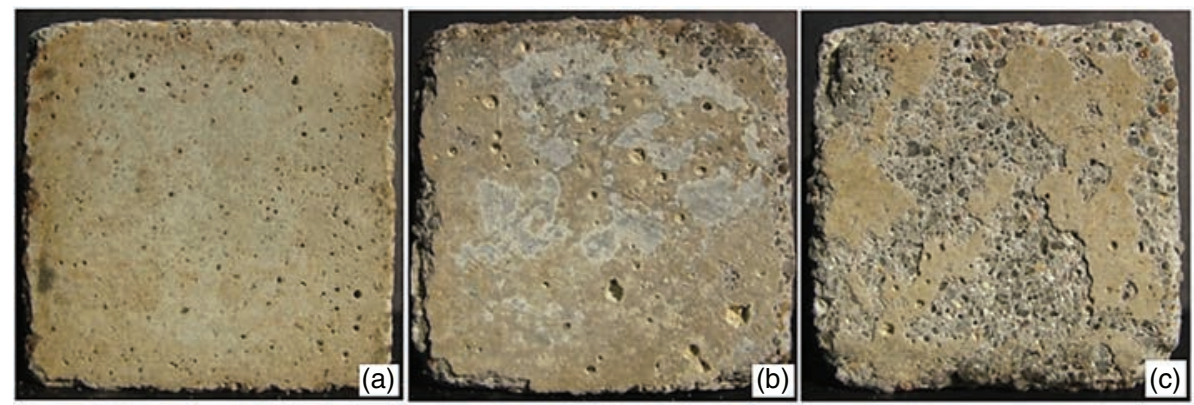

FIgURE 2. Mortar specimens of (a) CAPSCC, (b) PC5, and (c) PC2 exposed to 5\% magnesium sulphate solution for 12 months.

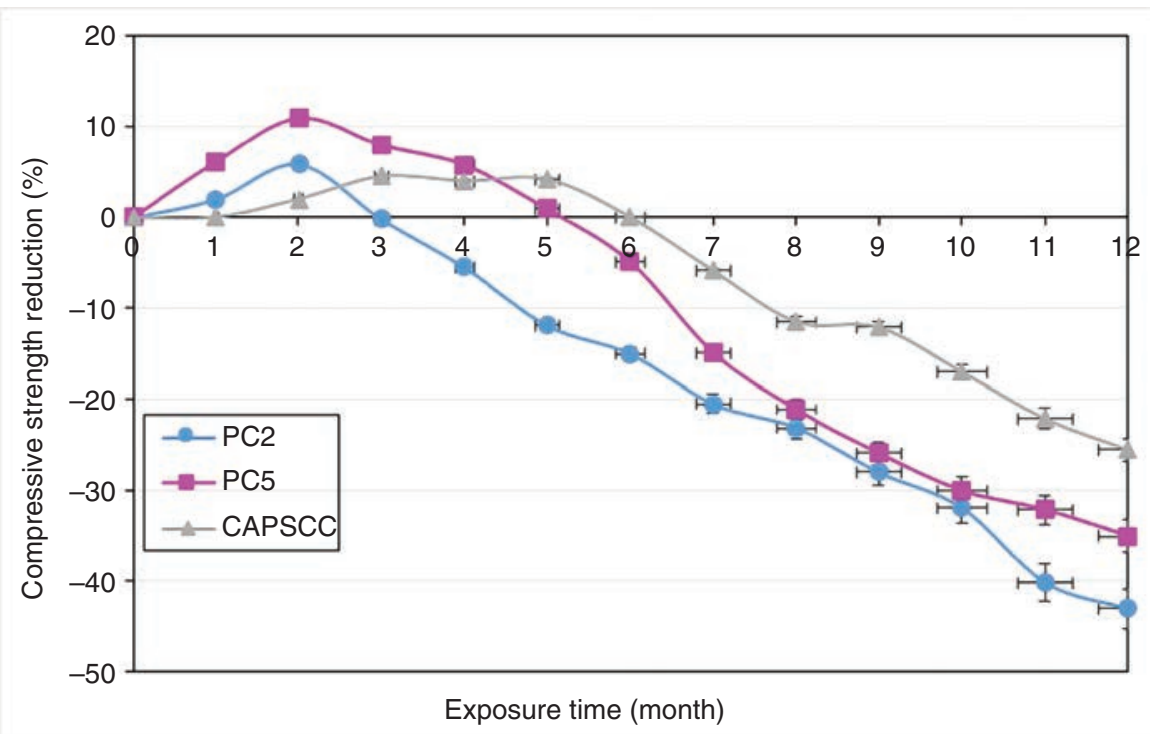

FIGURE 3. Compressive strength reduction of mortar specimens exposed to $5 \%$ magnesium sulphate solution.

presented in Figure 3. As observed in this figure, compressive strength of all specimens has firstly increased during the first few months of the exposure time. This limited increase in compressive strength is due to the progress of hydration reactions inside the specimens and probably to a lesser extent to the deposition of gypsum at regions close to the exposed surfaces resulting in densification. Compressive strengths of $\mathrm{PC} 2$ and PC5 mortar specimens reached their maximum values after two months of exposure, while CAPSCC mortars specimens attained their maximum compressive strength after about 3 months of exposure. Continued exposure, however, resulted in continuous compressive strength reduction. The compressive strength reduction of PC2, PC5, and CAPSCC mortar specimens after 12 months of exposure to $5 \%$ magnesium sulphate solution is $43.5 \%, 35.2 \%$, and $25.2 \%$, respectively. In other words, after 12 months of magnesium sulphate attack, the compressive strength reduction in PC2 and PC5 specimens were 1.7 and 1.4 times higher than that of CAPSCC mortar specimens, respectively.

It has been reported that composite cements containing pozzolanic materials exhibit an improved sulphate resistance compared to the corresponding plain control cements. Two main reasons have been stated for this behavior including; 1) consumption of $\mathrm{CH}$ in pozzolanic reactions and 2) decelerated decomposition of CSH (24). In the present study, CAPSCC shows a significantly higher resistance against magnesium sulphate compared to both PC2 and PC5. This result is in agreement with the findings of Sokkary et al. (46), Al-Dulaijan et al. (49), and Dong and Lin (50). Sokkary et al. (46) concluded that production of additional or secondary CSH gel is a possible reason for better magnesium sulphate resistance of pozzolanic cements. Al-Dulaijan et al. (49) reported that this desirable performance is due to decreased gypsum deposition, $\mathrm{C}_{3} \mathrm{~A}$ phase dilution, and dense structure resulted from pozzolanic reactions. 


\subsection{Length change}

The length changes of PC2, PC5, and CAPSCC mortar bars exposed to $5 \%$ magnesium sulphate solution for 12 months are depicted in Figure 4. As seen in this figure, all mortar bars exposed to magnesium sulphate solution have experienced increased length over time. Expansions of PC2, PC5, and CAPSCC mortar bars after 12 months of immersion in 5\% magnesium sulphate solution are $0.136 \%$, $0.11 \%$, and $0.026 \%$, respectively. The minimum and maximum length changes are related to CAPSCC and PC2 mortar bars, respectively. Inasmuch as mortars that have been subjected to magnesium sulphate solution have less length change, few studies have been conducted in this field and most cases have investigated the length change of mortars placed in sodium sulphate solution. The length change trend observed in the present study is in agreement with the results published by Santhanam et al (22). It has been reported that the uniform length change of mortars is due to the growth of surface brucite layer and also less length change of supplementary materials-based mortars compared to ordinary Portland cement is because of the less formation of gypsum and ettringite (22).

Relatively reduced expansion in mortar specimens exposed to magnesium sulphate solution compared to expansion in sodium sulphate attack can probably be attributed to the formation of brucite layer on the exposed surfaces. Since this layer acts as a protective layer, diffusion of sulphate ions into the cement matrix is limited, decelerating the formation and deposition of voluminous products such as gypsum. This layer can also result in reduced expansion of specimens by creating unstable conditions for ettringite as the most important expanding product.

\subsection{Weight change}

Figure 5 shows weight changes of PC2, PC5, and CAPSCC mortar specimens exposed to $5 \%$ magnesium sulphate solution for 12 months. PC2 and PC5 mortar specimens show continuous weight increase during the first 7 and 6 months of exposure time, respectively. PC2 mortar specimens exhibits a little bit higher weight increase than PC5 mortar specimens in the first half of the exposure time. In the second half of the exposure time, they show a different weight change trend in a zigzag form. This new weight change trend was caused by detachment of surface fragments including paste and sand debris and also small parts of brucite layer. Brucite layer is not stable forever and extensive growth of which upon continued exposure results in its cracking and breaking down. Such a trend in weight change has also been observed in results obtained by Biricik et al. (35). CAPSCC mortar specimens, however, show a uniform weight increase not only in the first half of the exposure time, but also in the second half of which. The amount of weight increase for CAPSCC mortar specimens in the first half of the exposure time is significantly lower than weight increases measured for PC2 and PC5 mortar specimens. Biricik et al. (35), however, observed further weight changes in pozzolanic mortars. They suggested that the decomposition of CSH gel into gypsum and brucite due to the magnesium sulphate attack causes weight loss.

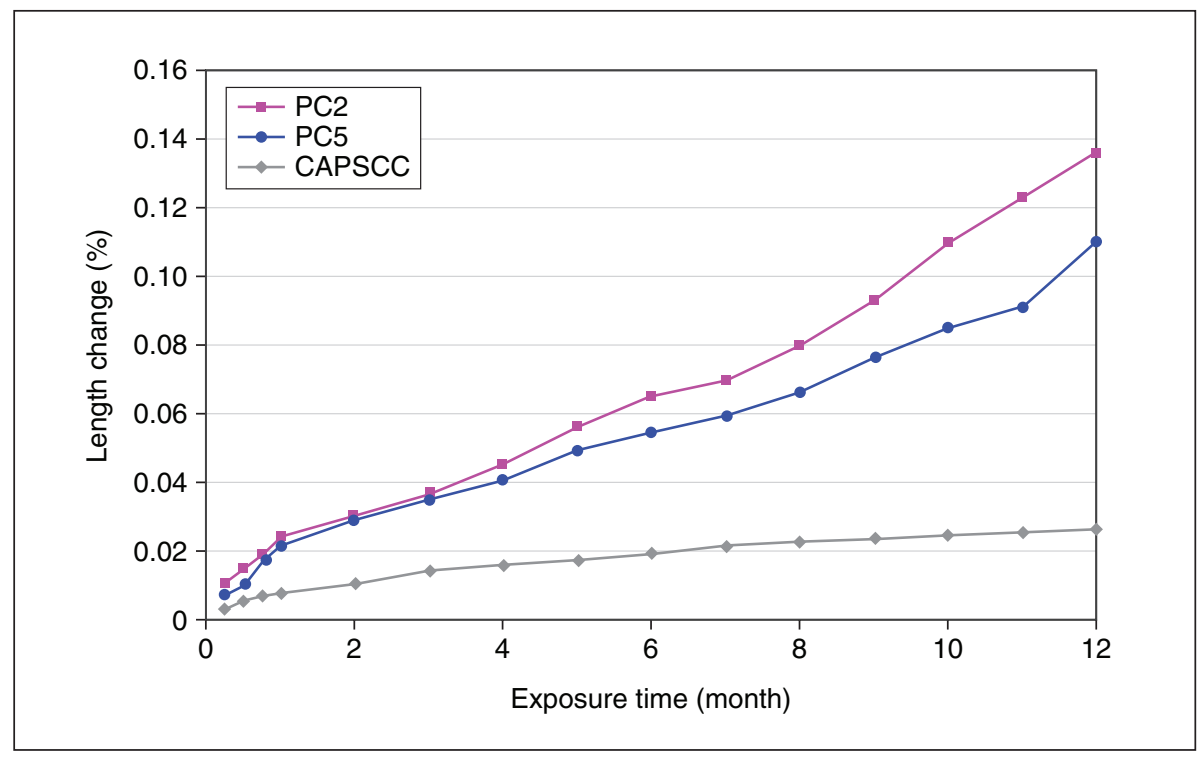

FIGURE 4. Length change of mortar bars exposed to 5\% magnesium sulphate solution. 


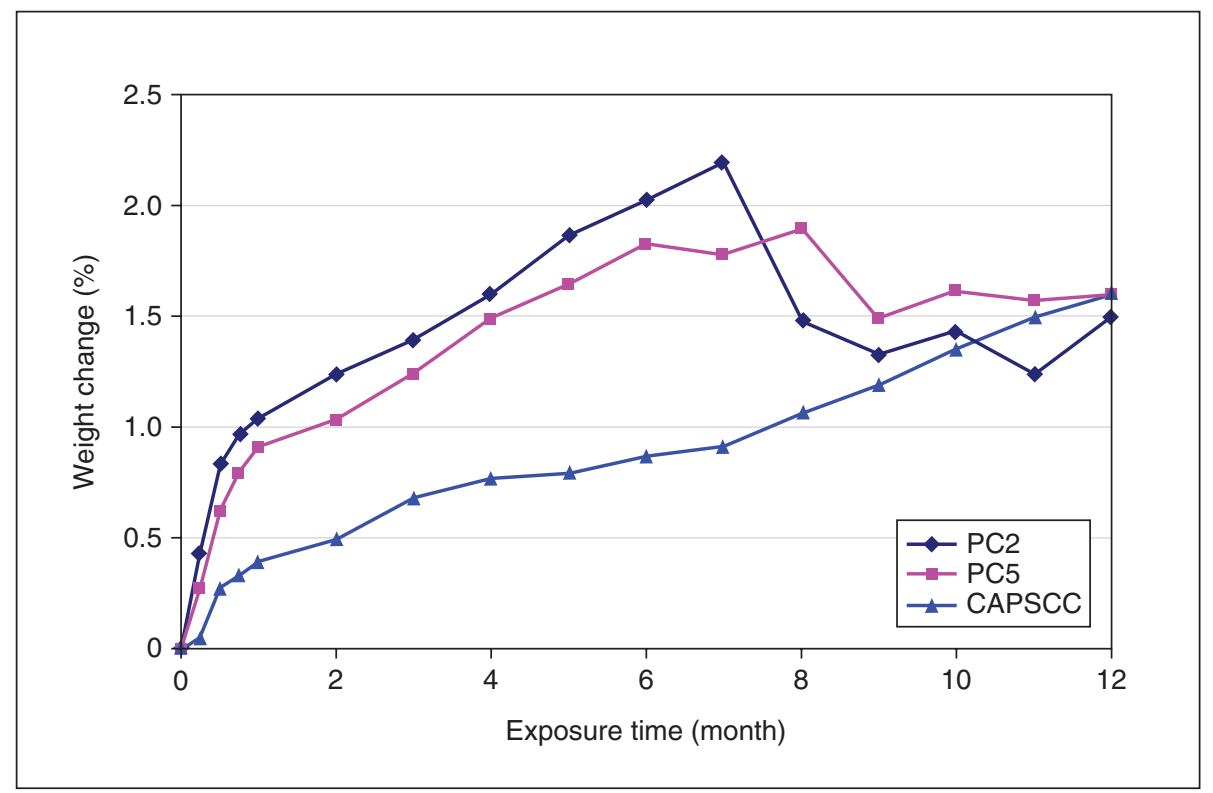

FIGURE 5. Weight change of mortar specimens exposed to $5 \%$ magnesium sulphate solution.

\subsection{X-ray diffraction analysis}

$\mathrm{X}$-ray diffraction (XRD) analysis was performed for supplementary studies supporting the results of compressive strength reduction and length/weight changes. XRD patterns of PC2, PC5, and CAPSCC hardened pastes exposed to $5 \%$ magnesium sulphate solution for 10 months are shown in Figure 6.

As can be seen, no ettringite phase was observed in all paste specimens. In the case of CAPSCC, low-intensity peaks of gypsum and Portlandite are seen compared to PC2 and PC5. The intensity of brucite peaks in CAPSCC is also less than those in $\mathrm{PC} 2$ and PC5. As will be confirmed later by scanning electron microscopy studies, CAPSCC mortar specimens developed a much thinner surface brucite layer than PC2 and PC5 mortar specimens. In magnesium sulphate attack, sulphate ions firstly react with $\mathrm{CH}$ present in the mortar structure and form brucite and gypsum. Deposition of brucite and gypsum on the exposed surfaces and inside the microstructure, respectively, creates a temporary protective effect against sulphate attack. With continuation of attack and diffusion of more sulphate ions across brucite layer and inside the microstructure, ettringite is produced in regions close to the surface. These materials fill the pores existed in the mortar structure causing porosity reduction in the mortar and consequently, resulting in compressive strength increase. With more production of gypsum and ettringite and continued pore-filling effect, the pressure exerted on the walls of the pores increases and this can finally results in the creation of cracks in the mortar matrix. Formation of the cracks provides shorter diffusion paths for the attacking ions. The penetration depth of sulphate ions within the mortar structure, therefore, increases.

Due to the low saturation $\mathrm{pH}$ value of brucite on the surface of the specimens and also where brucite is formed, ettringite becomes unstable and decomposes into gypsum and aluminum hydroxide (ettringite is stable between $\mathrm{pH}$ values of 11.4 and $12.4(51))$. No peaks related to ettringite have been observed in XRD patterns of pastes exposed to magnesium sulphate. With consumption of $\mathrm{CH}$ by sulphate ions and production of brucite, and due to lowered $\mathrm{pH}$ of the pore solution, $\mathrm{CSH}$ decomposes to produce $\mathrm{CH}$ and stabilize $\mathrm{pH}$. Because of the presence of sulphate ions in the solution and their continuous diffusion into the mortar specimens, the produced $\mathrm{CH}$ is immediately converted to gypsum by means of sulphate ions. With continuation of magnesium sulphate attack and reduced $\mathrm{CH}$ contents, the aggressive ions directly attack CSH and produce non-cementing phases such as magnesium silicate hydrate or silica gel. The decomposition of $\mathrm{CSH}$ and the formation of gypsum can be considered as two main mechanisms for structural deterioration of the mortar and compressive strength loss in specimens exposed to magnesium sulphate.

Due to their high amount of $\mathrm{C}_{3} \mathrm{~S}$ and $\mathrm{C}_{2} \mathrm{~S}, \mathrm{PC} 2$ and PC5 produce a lot of $\mathrm{CH}$ in their structure resulting in more gypsum formation and deposition as a result of reaction with magnesium sulphate, and, because of cracks created in the mortar structure, sulphate ions penetrate more deeply. Also, formation of cracks due to extensive gypsum deposition results in compressive strength reduction. Since the main mechanisms of the deterioration of specimens exposed to magnesium sulphate solution 


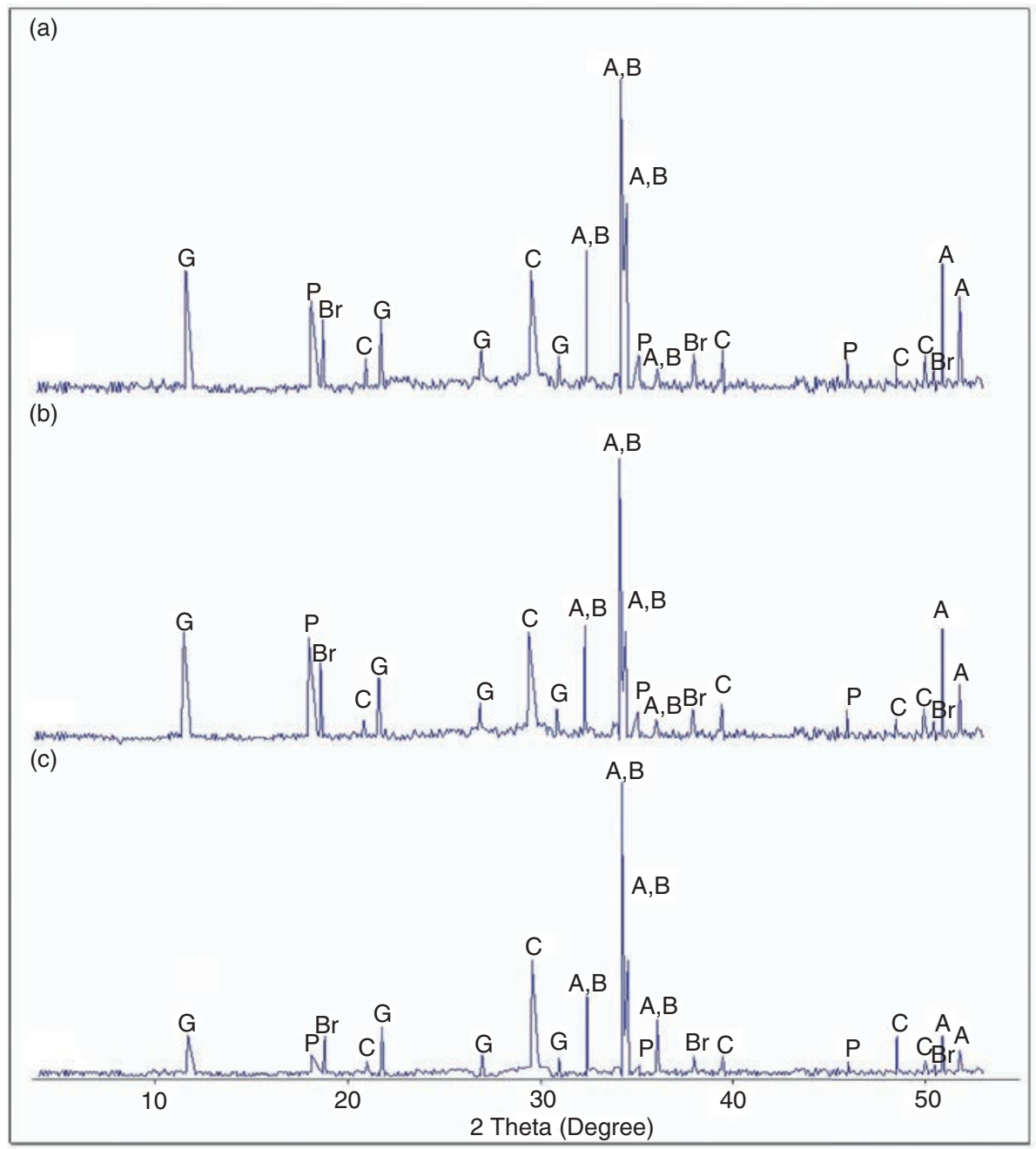

FIgURE 6. XRD patterns of a) PC2, b) PC5, and c) CAPSCC pastes exposed to 5\% magnesium sulphate solution for 10 months. (A: Alite, B: Belite, C: Calcite, P: Portlandite, Br: Brucite, G: Gypsum).

are formation of gypsum and CSH decomposition, PC5 with low $\mathrm{C}_{3} \mathrm{~A}$ has no special advantage, because very little ettringite is usually produced during the attack. CAPSCC produces low $\mathrm{CH}$ in its structure due to it only contains $14 \%$ of PC and to its possible pozzolanic property and thus resulting in the least gypsum deposition as a result of exposure to magnesium sulphate and compared to both PC2 and PC5. Consequently, CAPSCC mortar shows a smaller increase in compressive strength, which continues up to the fifth month of the exposure time. This is because porosity reduction in CAPSCC mortar structure due to gypsum deposition happens with less intensity over a longer time period. This less-intensity gypsum deposition in CAPSCC mortar is less deteriorative and the first reduction of compressive strength was therefore detected lately at the sixth month of exposure compared to PC2 and PC5, which showed the first sign of deterioration three months sooner (at the third month of exposure). Moreover, the production of additional CSH in CAPSCC mortar results in the formation of a denser microstructure with reduced permeability, which significantly decelerates the diffusion of sulphate ions into the mortar structure. As the result of these factors, CAPSCC exhibits a much better performance against magnesium sulphate attack compared to PC2 and PC5.

\subsection{Scanning electron microscopy studies}

SEM images of the brucite surface layers on the exposed surface of PC2, PC5, and CAPSCC paste specimens after 10 months of exposure to $5 \%$ magnesium sulphate solution are shown in Figure 7. As previously mentioned, this layer provides a temporary protective effect that can decelerate the diffusion of sulphate ions for a while. SEM observations confirmed that thickness and structure of this layer in PC2 and 

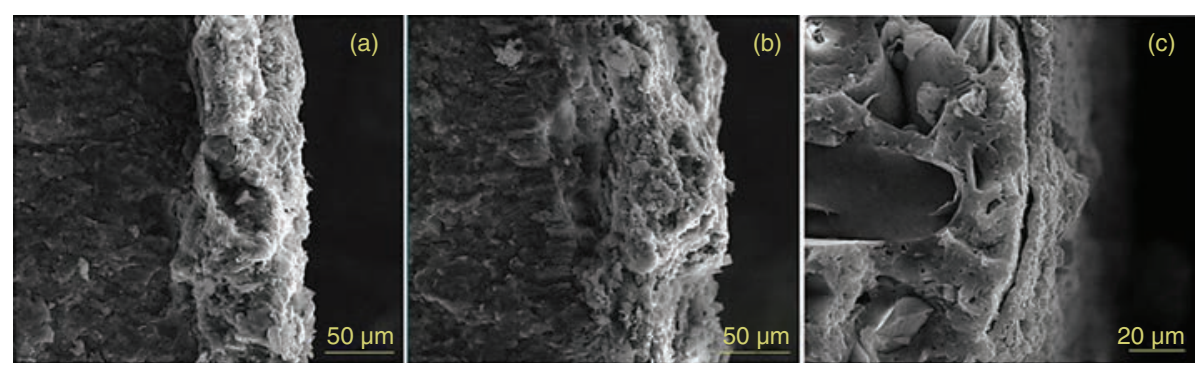

FIGURE 7. SEM images of brucite layers in a) PC2, b) PC5, and c) CAPSCC pastes exposed to $5 \%$ magnesium sulphate solution for 10 months.

PC5 pastes were approximately similar to each other. As seen in Figure 7, after 10 months of exposure, brucite layers of almost $60 \mu \mathrm{m}$-thickness were developed on PC2 and PC5 paste surfaces. In the case of CAPSCC paste, however, the observed brucite layer was much thinner. As Figure 7c shows, a 10-month exposure time resulted in the formation of an almost $10 \mu \mathrm{m}$-thick brucite layer. Such a difference in brucite layer formation between PCs and CAPSCC can be attributed to the low amount of $\mathrm{CH}$ in CAPSCC, and the hydraulic production of additional CSH from PHS activation which reduce the vulnerability of CAPSCC against magnesium sulphate attack.

\section{CONCLUSIONS}

Resistance of chemically-activated phosphorus slag-based composite cement (CAPSCC) mortar against magnesium sulphate attack at various exposure times up to one year was evaluated within the scope of this study. Also, standard mortars of both type II and V Portland cements (PC2 \& PC5) were used as reference for comparison purposes. Visual observations revealed significantly lesser signs of deterioration in CAPSCC compared to PC2 and PC5. After 12 months of continuous magnesium sulphate attack, the compressive strength reduction in PC2 and PC5 specimens were 1.7 and 1.4 times higher than that of CAPSCC mortar specimens, respectively. In addition, CAPSCC mortar specimens showed the least changes in both length and weight in comparison to PC2 and PC5 mortar specimens. The better performance of CAPSCC against magnesium sulphate attack compared to PC2 and PC5 is attributed to the consequences of pozzolanic reactions of phosphorus slag, which consume calcium hydroxide of the cement paste and produce additional CSH. Studies by XRD and SEM indicated that CAPSCC developed a much thinner brucite layer than PC2 and PC5.

\section{REFERENCES}

1. Hossain, M.M.; Karim, M.R.; Hossain, M.K.; Islam, M.N.; Zain M.F.M. (2015) Durability of mortar and concrete containing alkali-activated binder with pozzolans:
A review. Constr. Build. Mater. 93, 95-109. https://doi. org/10.1016/j.conbuildmat.2015.05.094.

2. Komljenovic, M.; Bašcarevic, Z.; Marjanovic, N.; Nikolic, V. (2013) External sulfate attack on alkali-activated slag. Constr. Build. Mater. 49, 31-39. https://doi.org/10.1016/j. conbuildmat.2013.08.013.

3. Ramyar, K.; Inan, G. (2007) Sodium sulfate attack on plain and blended cements. Build. Environ. 42, 1368-1372. https://doi.org/10.1016/j.buildenv.2005.11.015.

4. Aydın, S.; Yazıcı, H.; Yigiter, H.; Baradan, B. (2007) Sulfuric acid resistance of high-volume fly ash concrete. Build. Environ. 42 [2], 717-721. https://doi.org/10.1016/j. buildenv.2005.10.024.

5. Girardi, F.; Vaona, W.; Di Maggio, R. (2010) Resistance of different types of concretes to cyclic sulfuric acid and sodium sulfate attack. Cem. Concr. Compos. 32, 595-602. https://doi.org/10.1016/j.cemconcomp.2010.07.002.

6. Bassuoni, M.T.; Nehdi, M.L. (2007) Resistance of selfconsolidating concrete to sulfuric acid attack with consecutive $\mathrm{pH}$ reduction. Cem. Concr. Res. 37 [7], 1070-1084. https://doi.org/10.1016/j.cemconres.2007.04.014.

7. Bakharev, T.; Sanjayan, J.G.; Cheng, Y.B. (2002) Sulfate attack on alkali-activated slag concrete. Cem. Concr. Res. 32 [2], 211-216. https://doi.org/10.1016/ S0008-8846(01)00659-7.

8. Xu, A.; Shayan, A.; Baburamani, P. (1998) Test methods for sulfate resistance of concrete and mechanism of sulphate attack. ARRB transport research Ltd.

9. Naik, N.N.; Jupe, A.C.; Stock, S.R.; Wilkinson, A.P.; Lee, P.L.; Kurtis, K.E. (2006) Multi-mode X-ray study of sodium and magnesium sulfate attack on Portland cement paste. JCPDS-International Centre for Diffraction Data, 63-72.

10. Veiga, K.K.; Gastaldini, A.L.G. (2012) Sulfate attack on a white Portland cement with activated slag. Constr. Build. Mater. 34, 494-503. https://doi.org/10.1016/j. conbuildmat.2012.02.090.

11. Hekal, E.E.; Kishar, E.; Mostafa, H. (2002) Magnesium sulfate attack on hardened blended cement pastes under different circumstances. Cem. Concr. Res. 32 [9], 14211427. https://doi.org/10.1016/S0008-8846(02)00801-3.

12. Park, Y.S.; Suh, J.K.; Lee, J.H.; Shin, Y.S. (1999) Strength deterioration of high strength concrete in sulfate environment. Cem. Concr. Res. 29 [9], 1397-1402. https://doi. org/10.1016/S0008-8846(99)00106-4.

13. Prasad, J.; Jain, D.K.; Ahuja, A.K. (2006) Factors influencing the sulphate resistance of cement concrete and mortar. Asian J. Civil Eng. (Building and Housing) 7 [3], 259-268.

14. Nehdi, M.; Hayek, M. (2005) Behavior of blended cement mortars exposed to sulfate solutions cycling in relative humidity. Cem. Concr. Res. 35 [4], 731-742. https://doi. org/10.1016/j.cemconres.2004.05.032.

15. Bonen, D.; Cohen, M.D. (1992) Magnesium sulfate attack on Portland cement paste-I. Microstructural analysis. Cem. Concr. Res. 22 [1], 169-180. https://doi. org/10.1016/0008-8846(92)90147-N.

16. Skalny, J;; Marchand, J. (2002) Sulfate attack on concrete. Taylor \& Francis e-Library, New York. 
17. Lukowski, P.; Salih, A. (2015) Durability of mortars containing ground granulated blast-furnace slag in acid and sulphate environment. Procedia Eng. 108, 47-54. https:// doi.org/10.1016/j.proeng.2015.06.118.

18. Hassan, A.; Mahmud, H.B.; Jumaat, M.Z.; Alsubari, B.; Abdulla, A.I. (2013) Effect of magnesium sulphate on self-compacting concrete containing supplementary cementitious materials. Adv. Mater. Sci. Eng. https://doi. org/10.1155/2013/232371.

19. Merida, A.; Kharchi, F. (2015) Pozzolan concrete durability on sulphate attack. Procedia Eng. 114, 832-837. https:// doi.org/10.1016/j.proeng.2015.08.035.

20. Bonen, D.; Cohen, M.D. (1992) Magnesium sulfate attack on Portland cement paste: II. Chemical and mineralogical analyses. Cem. Concr. Res. 22 [4], 707-718. https://doi. org/10.1016/0008-8846(92)90023-O.

21. Amin, M.M.; Jamaludin, S.B.; Pa, F.C.; Chuen K.K. (2008) Effect of magnesium sulfate attack on ordinary Portland cement mortars. Portugaliae Electrochimica Acta 26, 235-242.

22. Santhanam, M.; Cohen, M.D.; Olek, J. (2002) Mechanism of sulfate attack: a fresh look part 1. Summary of experimental results. Cem. Concr. Res. 32 [6], 915-921. https:// doi.org/10.1016/S0008-8846(02)00724-X

23. Santhanam, M.; Cohen, M.D.; Olek, J. (2001) Sulfate attack research-whither now?. Cem. Concr. Res. 31 [6], 845-851. https://doi.org/10.1016/S0008-8846(01)00510-5.

24. Aye, T.; Oguchi, C.T. (2011) Resistance of plain and blended cement mortars exposed to severe sulfate attacks. Constr. Build. Mater. 25 [6], 2988-2996. https://doi.org/10.1016/j. conbuildmat.2010.11.106.

25. Samanta, C.; Chatterjee, M.K. (1982) Sulfate resistance of portland-pozzolanic cements in relation to strength. Cem. Concr. Res. 12 [6], 726-734. https://doi. org/10.1016/0008-8846(82)90035-7.

26. Duda, A. (1987) Aspects of the sulfate resistance of steelwork slag cements. Cem. Concr. Res. 17 [3], 373-384. https://doi.org/10.1016/0008-8846(87)90001-9.

27. Torii, K.; Kawamura, M. (1994) Effects of fly ash and silica fume on the resistance of mortar to sulfuric acid and sulfate attack. Cem. Concr. Res. 24 [2], 361-370. https:// doi.org/10.1016/0008-8846(94)90063-9.

28. Gollop, R.S.; Taylor, H.F.W. (1996) Microstructural and microanalytical studies of sulfate attack. V. Comparison of different slag blends. Cem. Concr. Res. 26 [7], 1029-1044. https://doi.org/10.1016/0008-8846(96)00090-7.

29. Al-Amoudi, O.S.B. (1998) Sulfate attack and reinforcement corrosion in plain and blended cements exposed to sulphate environments. Build. Environ. 33 [1], 53-61. https://doi.org/10.1016/S0360-1323(97)00022-X.

30. Zelić, J.; Krstulović, R.; Tkalčec, E.; Krolo, P. (1999) Durability of the hydrated limestone-silica fume Portland cement mortars under sulphate attack. Cem. Concr. Res. 29 [6], 819-826. https://doi.org/10.1016/ S0008-8846(99)00049-6.

31. Aköz, F.; Türker, F.; Koral, S.; Yuzer, N. (1999) Effects of raised temperature of sulfate solutions on the sulphate resistance of mortars with and without silica fume. Cem. Concr. Res. 29 [4], 537-544. https://doi.org/10.1016/ S0008-8846(98)00251-8.

32. Lee, S.T.; Moon, H.Y.; Swamy, R.N. (2005) Sulfate attack and role of silica fume in resisting strength loss. Cem. Concr. Compos. 27 [1], 65-76. https://doi.org/10.1016/j. cemconcomp.2003.11.003.

33. Diab, A.M.; Awad, A.E.M.; Elyamany, H.E.; Abd Elmoaty, A.E.M. (2012) Guidelines in compressive strength assessment of concrete modified with silica fume due to magnesium sulfate attack. Constr. Build. Mater. 36, 311-318. https://doi.org/10.1016/j.conbuildmat.2012.04.075.

34. Sezer, G.I. (2012) Compressive strength and sulfate resistance of limestone and/or silica fume mortars. Constr. Build. Mater. 26 [1], 613-618. https://doi.org/10.1016/j. conbuildmat.2011.06.064.
35. Biricik, H.; Aköz, F.; Türker, F.; Berktay I. (2000) Resistance to magnesium sulfate and sodium sulphate attack of mortars containing wheat straw ash. Cem. Concr. Res. 30 [8], 1189-1197. https://doi.org/10.1016/ S0008-8846(00)00314-8.

36. Chatveera, B.; Lertwattanaruk, P. (2009) Evaluation of sulfate resistance of cement mortars containing black rice husk ash. J. Environ. Manage. 90 [3], 1435-1441. https:// doi.org/10.1016/j.jenvman.2008.09.001.

37. Chindaprasirt, P.; Paisitsrisawat, P.; Rattanasak, U. (2014) Strength and resistance to sulfate and sulfuric acid of ground fluidized bed combustion fly ash-silica fume alkali-activated composite. Adv. Powder Technol. 25 [3], 1087-1093. https://doi.org/10.1016/j.apt.2014.02.007.

38. Nehdi, M.L.; Suleiman, A.R.; Soliman, A.M. (2014) Investigation of concrete exposed to dual sulfate attack. Cem. Concr. Res. 64, 42-53. https://doi.org/10.1016/j. cemconres.2014.06.002.

39. Saca, N.; Georgescu, M. (2014) Behavior of ternary blended cements containing limestone filler and fly ash in magnesium sulfate solution at low temperature. Constr. Build. Mater. 71: 246-253. https://doi.org/10.1016/j. conbuildmat.2014.08.037.

40. Yusuf, M.O. (2015) Performance of slag blended alkaline activated palm oil fuel ash mortar in sulfate environments. Constr. Build. Mater. 98: 417-424. https://doi.org/10.1016/j. conbuildmat.2015.07.012

41. Xia, C.; Li, Z.; Kunhe, F. (2009) Anti-crack performance of phosphorous slag concrete. Wuhan Uni. J. Nat. Sci. 14 [1], 080-086. https://doi.org/10.1007/s11859-009-0117-9.

42. Xia, C.; Kunhe, F.; Huaquan, Y.; Peng, H. (2011) Hydration kinetics of phosphorous slag-cement paste. Wuhan Uni. J. Technol-Mater. 26 [1], 142-146. https://doi.org/10.1007/ s11595-011-0186-4.

43. Allahverdi, A.; Mahinroosta, M. (2013) Mechanical activation of chemically activated high phosphorous slag content cement. Powder Technol. 245, 182-188. https://doi. org/10.1016/j.powtec.2013.04.037.

44. Allahverdi, A.; Pilehvar, S.; Mahinroosta, M. (2016) Influence of curing conditions on the mechanical and physical properties of chemically-activated phosphorous slag cement. Powder Technol. 288: 132-139. https://doi. org/10.1016/j.powtec.2015.10.053.

45. Allahverdi, A.; BahriRashtAbadi, M.M. (2014) Resistance of chemically activated high phosphorous slag content cement against frost-salt attack. Cold Reg. Sci. Technol. 98, 18-25. https://doi.org/10.1016/j.coldregions. 2013.11.001.

46. Sokkary, T.M.; Assal, H.H.; Kandeel, A.M. (2004) Effect of silica fume or granulated slag on sulphate attack of ordinary portland and alumina cement blend. Ceram. Int. 30 [2], 133-138. https://doi.org/10.1016/ S0272-8842(03)00025-7.

47. Allahverdi, A.; Saffari, M. (2011) Chemical activation of phosphorous slag with a solid compound activator. Proceedings of $4^{\text {th }}$ International Conference on NonTraditional cements and Concretes 27-30 June, Brno, Czech Republic, 573-580.

48. Allahverdi, A.; Rahmani, A. (2009) Chemical activation of natural pozzolan with a solid compound activator. Cement Wapno Beton. 4, 205-213.

49. Al-Dulaijan, S.U. (2007) Sulfate resistance of plain and blended cements exposed to magnesium sulphate solutions. Constr. Build. Mater. 21, 1792-1802. https://doi. org/10.1016/j.conbuildmat.2006.05.017

50. Dong-xu, L.; Lin, C. (2002) A blended cement containing blast furnace slag and phosphorous slag. J. Wuhan Uni. Technol-Mater. Sci. Ed. 17 [2], 62-65. https://doi. org/10.1007/BF02832625.

51. Damons, R.E., Petersen, F.W. (2002) An aspen model for the treatment of acid mine water. The European J. Mineral Processing Environ. Protection 2 [2], 69-81. 